\title{
EFFECTS OF DWARF MISTLETOE ON CLIMATE RESPONSE OF MATURE PONDEROSA PINE TREES
}

\author{
SHARON STANTON* \\ Department of Biology \\ Portland State University \\ PO Box 751 \\ Portland, OR 97207-0751, USA
}

\begin{abstract}
This research examines the influence of western dwarf mistletoe (Arceuthobium campylopodum) infection on the radial growth response of mature ponderosa pines (Pinus ponderosa) and its effects on dendroclimatic reconstructions. I hypothesize that trees with mistletoe have lower annual growth rates than uninfected trees, but exhibit higher mean sensitivities and stronger relationships between growth and climate variation. I tested these hypotheses using correlation and regression analyses to compare 100-year crossdated and standardized tree-ring chronologies from 26 infected and 29 uninfected trees. I compared both chronologies to climate variation as measured by changes in total precipitation, minimum, mean, and maximum temperature, and the Palmer Drought Severity Index (PDSI). Results show that trees infected with dwarf mistletoe have higher radial growth rates, exhibit greater sensitivity, and respond more strongly to climate variation. Both infected and uninfected chronologies are significantly correlated with the respective climate variables, but exhibit different patterns. The strongest correlations are between infected trees and PDSI for all months tested; significant correlations between uninfected trees and PDSI are limited to May through December lagged from the previous year. These results suggest mistletoe-infected trees are more sensitive to climatic factors than uninfected trees and may be useful for dendroclimatic analyses.
\end{abstract}

Keywords: dwarf mistletoe, ponderosa pine, dendroclimatology, dendroecology.

\section{INTRODUCTION}

Site selection and targeting climate sensitive trees is an essential component of dendroclimatological research. It is important to select trees that have a specific factor that limits growth of annual rings. To reduce the influence of endogenous disturbances on ring formation in sample trees, dendroclimatologists historically avoid selecting trees with evidence of physical damage or disease, including infection by parasitic plants such as mistletoes (Fritts 1976; Stokes and Smiley 1996). Despite this protocol, little is known about how parasitic plants alter the usefulness of host trees for dendroclimatological studies, and their dispersal mechanism results in clumped distributions, making it difficult to find uninfected trees in certain locations.

\footnotetext{
*sstanton@pdx.edu
}

The dwarf mistletoes (Arceuthobium: Viscaceae) are a group of obligate vascular hemiparasites found on a wide range of conifers in North America, Asia, Europe, and parts of Africa (Hawksworth and Wiens 1996; Geils and Hawksworth 2002). Mistletoes use an endophytic system inside host branches to take up water, minerals, and carbohydrates from host trees (Knutson 1983; Lamont 1983), leading to several physiological and morphological changes in the tree. Increased host mortality rates, reduced height and diameter growth, and reduction of wood quality are typical results of mistletoe infection (Hawksworth and Wiens 1996; Thomson et al. 1997; Geils and Collazo 2001; Geils and Hawksworth 2002). Infection alters host foliage growth and respiration rates (Tocher et al. 1984), ultimately altering water relations within host tissue (Fisher 1983; Wilson and Calvin 1996). 
Changes in host water relations and biomass allocation suggest that infected trees are more sensitive to annual changes in precipitation and temperature. Several studies have demonstrated that transpiration rates of dwarf mistletoe shoots are higher than those of host tissues, which may increase both water stress in the host and allocation of resources to mistletoe shoots (Fisher 1983; Tocher et al. 1984; Wilson and Calvin 1996). Additional evidence indicates that infection increases needle surface area while decreasing volume (Tinnin and Knutson 1980; Wanner and Tinnin 1986). Such shifts in the distribution of biomass in the host crown could lower water-use efficiency, resulting in lower tolerance to drought stress (Sala et al. 2001). Sala et al. (2001) also reported that foliage in infected branches has lower water-use efficiency when compared to uninfected branches in Douglas-fir (Pseudotsuga menziesii Mirb.) and western larch (Larix occidentalis Nutt.), which differ from ponderosa pine in their morphological response to infection.

The majority of research on dwarf mistletoes focuses on host plant productivity (Wanner and Tinnin 1989), economic impacts (Hawksworth and Shaw 1984), and control of spread in second growth stands (Hawksworth and Wiens 1996). Studies of physiological effects of mistletoe on mature, unmanaged trees are rare (Shea 1962; Childs and Wilcox 1966). Few studies have investigated the physiological response of host trees in terms of specific climate variables.

This study investigates the influence of dwarf mistletoe on host tree response to climate to determine the necessity or advantages for dendrochronologists to avoid sampling infected trees. Compared to uninfected trees, I expect infected trees to exhibit: 1) lower growth rates, 2) higher mean sensitivities, and 3) stronger correlations with climate variables. The negative influence of mistletoe on radial growth is well documented (Geils and Hawksworth 2002, Stanton 2006), so I expect to see low growth rates among the severely infected individuals sampled. Decreased growth rates could result in a stronger response to climate variation as infected trees experience increased moisture stress and nutrient loss to mistletoe plants. Therefore, I hypothesize that infected trees will have more sensitive ring-width series and stronger correlations with climate variables.

\section{METHODS}

\section{Study Area}

The study area is located in central Oregon, within the Newberry National Volcanic Monument (NNVM) in the Deschutes National Forest $\left(43.69^{\circ} \mathrm{N}, 121.25^{\circ} \mathrm{W}\right.$; Fig. 1$)$. The study site is characterized by 11 kipukas (forest isolates) located within shallow, mid-Holocene lava flows (Peterson and Groh 1969). Sizes of the kipukas range from 0.4 to 113 ha, with maximum elevations from 1590 to $1820 \mathrm{~m}$. A few logs and stumps resulting from recent fire suppression efforts are the only evidence of anthropogenic disturbance among the kipukas I sampled.

The regional climate of the study area is strongly influenced by the rainshadow effect from the Cascade Mountains to the west. The moisture regime is semi-arid, with the majority of precipitation occurring from October to March, usually as snow during the winter. Average annual precipitation is $c a .300 \mathrm{~mm}$, and average temperatures range from a low of $0^{\circ} \mathrm{C}$ in January to a high of $17.3^{\circ} \mathrm{C}$ in July (OCS 2005).

The forests of the kipukas are dominated by three tree species, and distributions appear to be topographically and edaphically controlled. Ponderosa pine (Pinus ponderosa var. ponderosa) is most common on south-facing slopes, while northfacing slopes and interior stands are dominated by white fir-grand fir hybrids (Abies concolor-A. grandis). Flat areas are typically dominated by dense stands of lodgepole pine (Pinus contorta var. murryana). Western white pine (Pinus monticola) and quaking aspen (Populus tremuloides) are found at a few locations.

Two species of dwarf mistletoe occur in the study area-Arceuthobium americanum Nutt. is found predominantly on lodgepole pine, and $A$. campylopodum Engelm. typically infects ponderosa pine. The distribution and density of dwarf mistletoe across the study area is highly variable, with some kipuka having no mistletoe and others having mistletoe in the majority of pine-dominated stands. The stands with mistletoe are moder- 


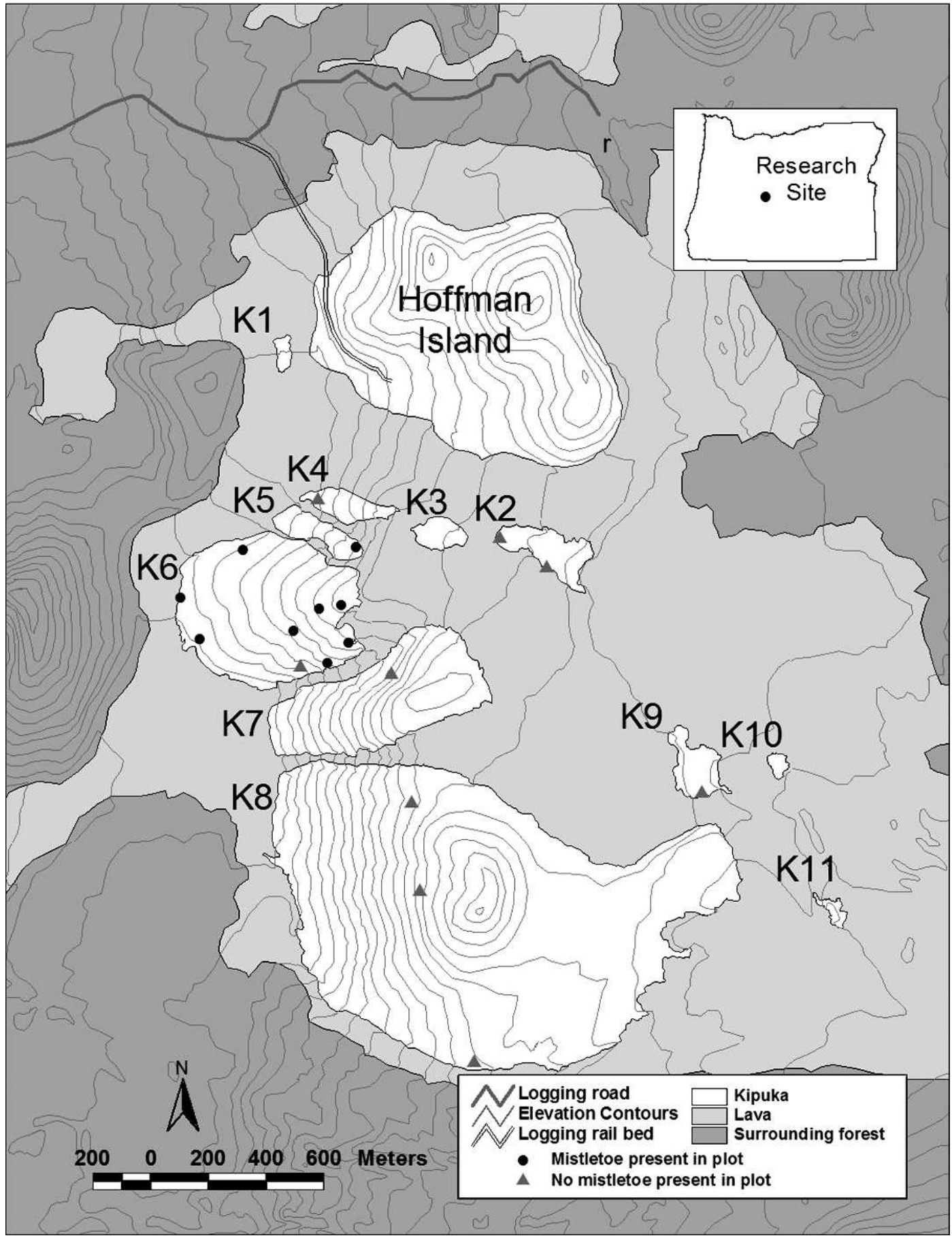

Figure 1. Location of study site and sampled stands at Newberry National Volcanic Monument in central Oregon. Black circles represent sampled stands that are infected with dwarf mistletoe; gray triangles indicate sampled stands without dwarf mistletoe. 
Table 1. Summary statistics (mean and standard deviation) and t-test results for the infected and uninfected chronologies, and a truncated Lava Cast Forest (LCF) chronology using data provided by Pohl et al. (2002). Ring-width indices representing growth rates are the averaged and standardized annual growth increment for all sample trees in the chronology.

\begin{tabular}{lccccccc}
\hline & $\begin{array}{c}\mathrm{Stand} \mathrm{BA}^{\mathrm{a}} \\
\left(\mathrm{m}^{2} / \mathrm{ha}\right)\end{array}$ & $\begin{array}{c}\mathrm{DBH}^{\mathrm{b}} \\
(\mathrm{cm})\end{array}$ & $\begin{array}{c}\text { Age }^{\mathrm{b}} \\
(\mathrm{yrs})\end{array}$ & \# Segments/Flags & $\begin{array}{c}\text { Interseries } \\
\text { Correlation }\end{array}$ & $\begin{array}{c}\text { Mean } \\
\text { Sensitivity* }\end{array}$ & $\begin{array}{c}\text { Ring Width } \\
\text { Index* }\end{array}$ \\
\hline Infected & $48(19)$ & $55(18)$ & $284(61)$ & $96 / 5$ & $0.536(0.10)$ & $0.253(0.03)$ & $0.75(0.23)$ \\
Uninfected & $54(14)$ & $52(20)$ & $303(89)$ & $90 / 7$ & $0.521(0.09)$ & $0.232(0.04)$ & $0.64(0.17)$ \\
LCF & N/A & N/A & $285(104)$ & $97 / 2$ & $0.552(0.07)$ & $0.243(0.04)$ & $0.79(0.12)$ \\
All Sites & $51(18)$ & $54(20)$ & $293(74)$ & $283 / 31$ & $0.475(0.13)$ & $0.242(0.05)$ & $0.77(0.31)$ \\
\hline
\end{tabular}

* Infected and uninfected significantly different $(p<0.05)$.

${ }^{a}$ Mean basal area (BA) for the sample tree and 20 to 30 surrounding trees.

${ }^{\mathrm{b}}$ Mean diameter at breast height (DBH) and age for sample trees only.

ately to severely infested, meaning that the majority of trees support mistletoe in over half of their crowns.

The climate, topography, and lack of management make NNVM ideal for investigating the influence of mistletoe on the growth of mature trees. The semi-arid climate and short growing season indicate that moisture is the limiting factor for tree growth at NNVM, making it an appropriate location for dendroclimatic sampling. Drought-sensitive sample sites are located on southwest or west-facing slopes with angles ranging from 6 to $25^{\circ}$. Each sample site is located in mature (mean age $>157$ years) low density ( $c a$. 330 trees/ha) stands to ensure adequate sampling of mature trees with sensitive ring series.

\section{Field Methods}

I removed increment cores from 26 severely infected trees and 29 uninfected trees located on seven different kipukas (Fig. 1). Sample trees are located in 15 different stands dominated by large, mature ponderosa pine. I selected infected and uninfected trees of similar size and from similar stand conditions (Table 1) in order to control for differences in growth unrelated to mistletoe infection. The samples I used are part of a larger study investigating disturbance and succession across a fragmented landscape (Arabas et al. 2006; Hadley and Arabas in prep). The cores for this larger study were used to establish age structures, therefore only one core per tree was removed 30 to $50 \mathrm{~cm}$ from the base.

\section{Chronology Development}

Increment cores were prepared using standard dendrochronological techniques (Stokes and Smiley 1996). I crossdated samples using a combination of skeleton plots and the list method (Yamaguchi 1991). Ring widths were measured to the nearest $0.001 \mathrm{~mm}$ using a Velmex measuring system and Medir software (Holmes 1994). I used COFECHA (Holmes 1983) to verify crossdating of the infected and uninfected samples first together and then separately, as well as against a local climate reconstruction (Pohl et al. 2002). The measurement data were then truncated to begin in 1900 because of the unknown level of mistletoe infection prior to that time. Although I could not reconstruct historical mistletoe infection levels, mistletoes have long life cycles leading to relatively slow rates of spread (Hawksworth and Wiens 1996). Based on this knowledge, I assumed that a severely infected tree at present supported some level of mistletoe infection 100 years ago. The use of 100-year chronologies provided sufficient data for robust statistical analyses.

I standardized the ring-width indices for each tree and averaged them into separate mean chronologies for the infected versus uninfected samples using the program ARSTAN (Cook and Holmes 1999). Both standardized chronologies were detrended once using a linear regression line. The truncated time series allowed for the use of linear regression detrending to remove low-frequency signals unrelated to climate, without the need to remove growth trends. 


\section{Comparison of Means}

I tested for differences in annual growth variation between infected and uninfected chronologies. Paired t-tests were used to compare annual average ring width, expressed as the standardized ring-width index for each chronology. I compared mean sensitivities and interseries correlations between the infected and uninfected chronologies with independent sample t-tests. Additionally, differences in sample stand basal area, and sample tree ages and diameters were evaluated using an independent sample t-test.

\section{Correlations with Climate Variables}

I used Spearman's rank-order correlation analysis and linear regression to examine the relationship between climate variation and mean ring-widths from the standardized chronologies. Climate variables used in the analyses included: Palmer Drought Severity Index (PDSI) and total precipitation for Oregon Climate Division 7 for 20 months (the year of tree growth plus 8 months lagged from the previous year), mean, minimum, and maximum monthly temperatures from Bend, Oregon, for 12 months (the year of tree growth) (NCDC 2005). PDSI uses temperature, precipitation, soil moisture, and drought duration to measure the departure of moisture supply from average conditions (Palmer 1965). A positive PDSI indicates higher than average moisture availability, while a negative PDSI reflects lower than average moisture. I did not include analyses of climatic teleconnections such as Pacific Decadal Oscillation or El Niño Southern Oscillation because previous work found only weak relationships between those climate indices and growth of ponderosa pine at this study site (Pohl et al. 2002).

\section{RESULTS}

\section{Comparison of Means}

Uninfected trees exhibit lower mean ring widths than infected trees $(\mathrm{t}=-8.1, \mathrm{p}<0.01$, Table 1 and Fig. 2). Interseries correlations do not differ significantly between infected (0.536) and uninfected (0.521) samples. Mean sensitivity of the infected sample $(0.253)$ is significantly higher than the uninfected sample $(0.232, \mathrm{p}<0.05)$ (Table 1$)$. Mean sensitivities and interseries correlations are relatively low for ponderosa pine, but not unusual for the Pacific Northwest (Speer 1997; Pohl et al. 2002). Stand basal area and tree age and size do not differ between infected and uninfected samples (Table 1).

\section{Correlations with Climate Variables}

The dominant climate controls on growth differ between infected and uninfected trees. Palmer Drought Severity Index has the strongest relationship with both chronologies. The infected chronology is significantly correlated with PDSI for the current year and eight months lagged from the previous year (Fig. 3A). PDSI explains $48 \%$ of the variance in the infected chronology, with the previous November and current year July being the strongest predictors of growth $(\beta=1.36$ and 1.92, respectively). The uninfected chronology is significantly correlated with PDSI for the eight months lagged from the previous year and December of the current year (Fig. 3A). PDSI explains 36\% of the variance in the uninfected chronology, and July from both the previous and current growing year is the strongest predictor of growth $(\beta=1.06$ and 0.95 , respectively). Strong correlations with PDSI indicate that the chronologies are robust.

Precipitation and temperature are significantly correlated with both chronologies, but the response patterns differ. Infected tree growth is positively correlated with precipitation from June, August, and November lagged from the previous year (Fig. 3B). The uninfected chronology is negatively correlated with April precipitation (Fig. 3B). Average temperatures in March and July are negatively correlated with both chronologies, but the relationship is stronger for infected samples (Fig. 4A). June average temperature is also significantly correlated with the infected chronology. Minimum temperatures for March, April, and June to September are negatively correlated with growth for both chronologies, but stronger relationships exist for the uninfected chronology (Fig. 4B). In contrast, maximum temperatures have a weak relationship with tree growth, showing a significant correlation only 


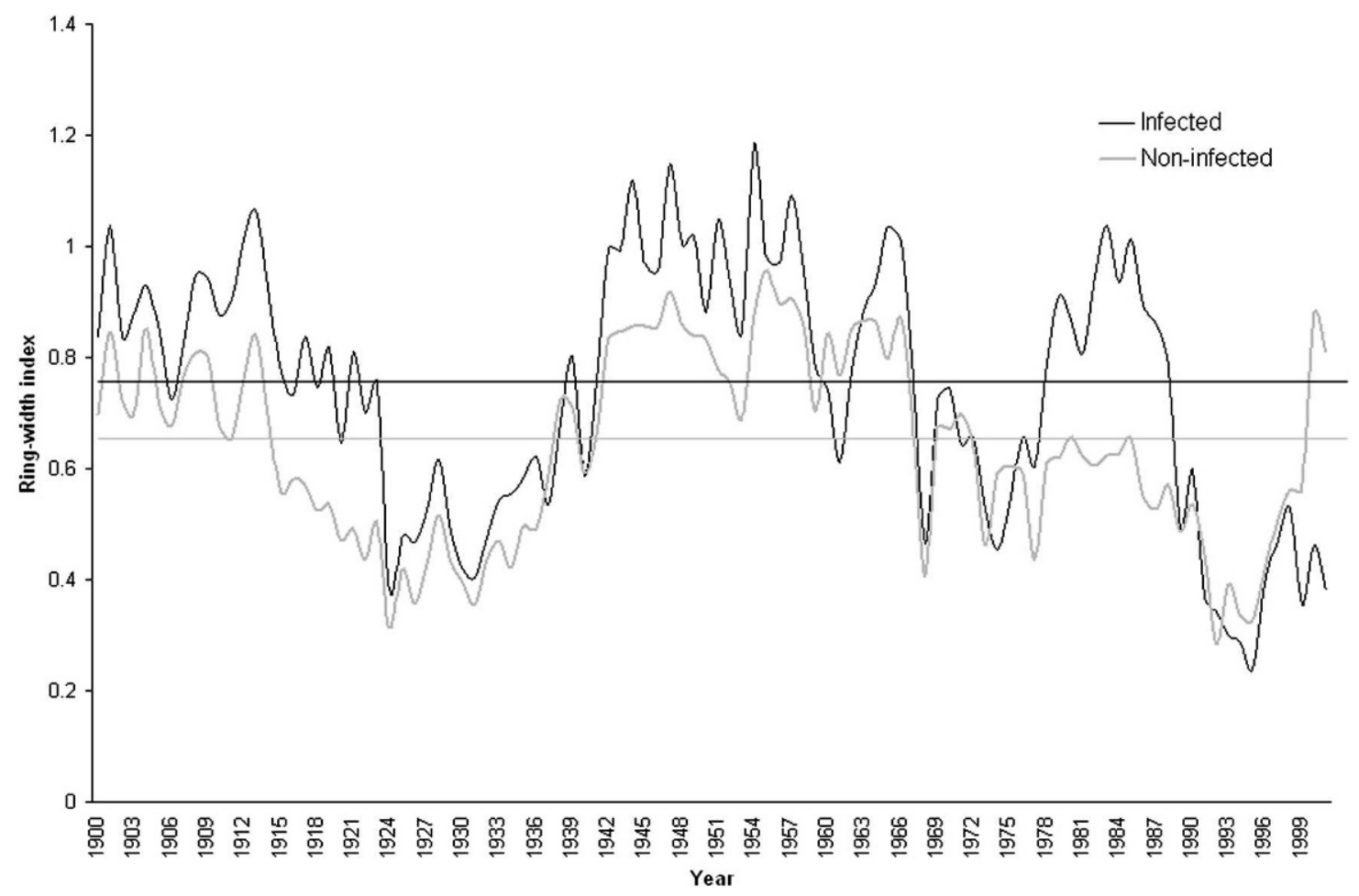

Figure 2. Mean ring-width chronologies for standardized, non-detrended measurements from 1900-2001. Horizontal lines indicate mean ring-width index for all series in the chronology (infected $=0.75$ and uninfected $=0.64$ ).

between June temperatures and the infected chronology $(\mathrm{r}=-0.25, \mathrm{p}<0.05)$ (Fig. 4C).

Infected trees are more sensitive to variations in climate and appear to grow more rapidly when conditions are favorable. During periods of high soil moisture (1915-1923 and 1980s), infected trees grew more rapidly than uninfected trees (Fig. 5). Infected trees grew less rapidly than uninfected when moisture supply is low (1940s and early 1960s), but the growth difference is less than during high soil moisture years. During years of extreme moisture stress as indicated by a very low PDSI (1930s and late 1960s), infected trees did not appear to have an advantage over uninfected trees and both grew poorly (Fig. 5).

\section{DISCUSSION}

\section{Mean Growth Rates}

The observation that infected sample trees tend to have higher radial growth rates than uninfected trees is not likely to be a function of age or competition because the sampled trees represent similar ages and are growing in comparable conditions. Several mechanisms may explain the unexpectedly high radial growth rates of infected trees. Previous studies demonstrated that mistletoe increases respiration and transpiration rates of host trees, which may lead to higher water use and metabolic rates in infected trees (Fisher 1983; Tocher et al. 1984). Higher metabolic rates would result in faster growth during periods of abundant resources. Changes in metabolism may explain the higher growth rates of infected trees in a semi-arid environment during years of high moisture availability. Similar results have been reported by Knapp et al. (2001) who found increased growth in western juniper resulting from atmospheric carbon dioxide fertilization, especially for trees experiencing moisture stress. These results suggest that carbon dioxide fertilization could disproportionately influence growth of infected trees during dry years, but testing this idea requires a long-term history of mistletoe infection 

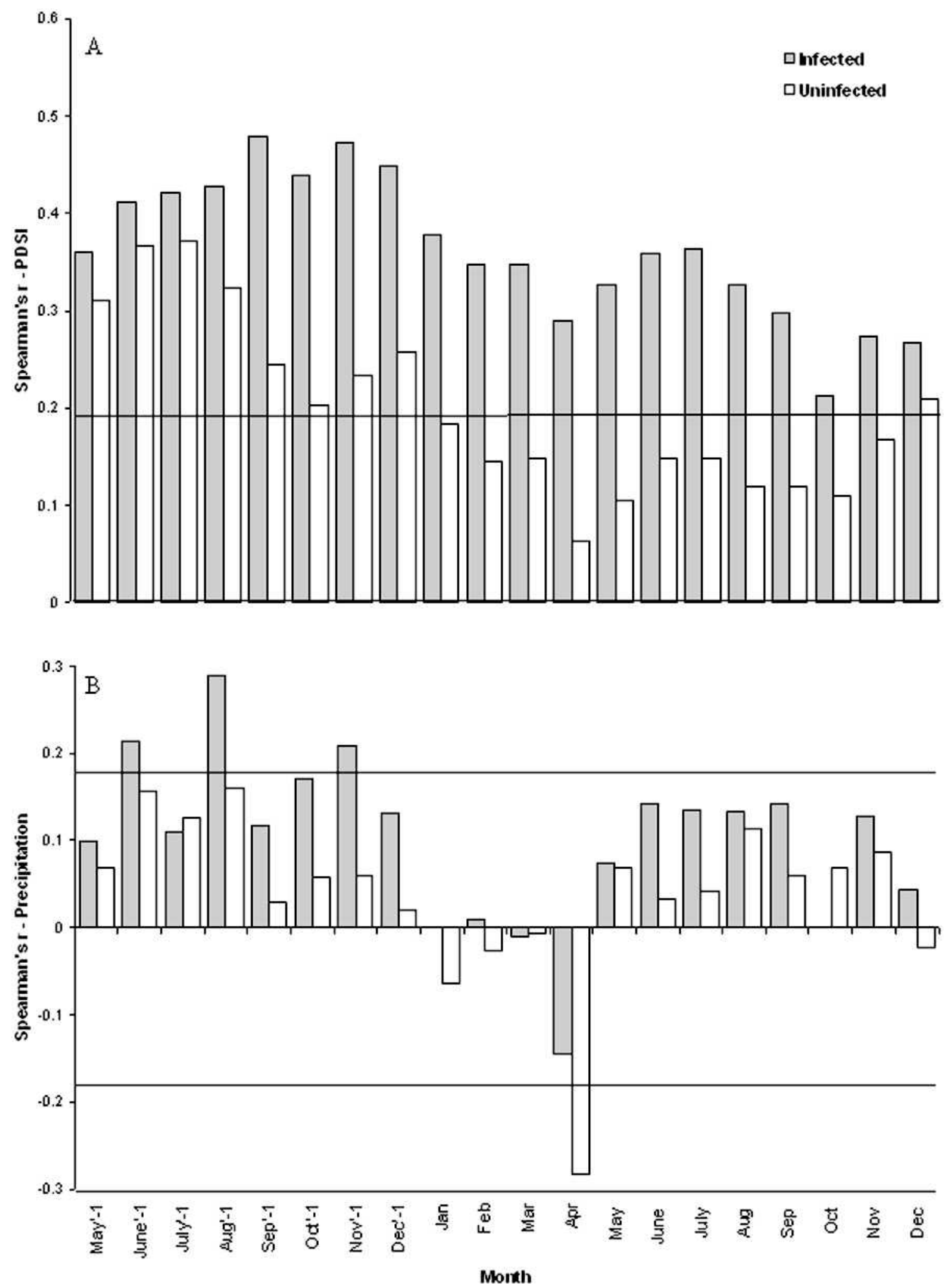

Figure 3. Spearman's correlation coefficients between standardized chronology index value for each year and A: Palmer Drought Severity Index, B: total monthly precipitation for each year plus 8 months lagged from the previous year. The horizontal line indicates the $95 \%$ confidence interval; therefore all correlations above that line are significant $(\mathrm{p}<0.05)$. 

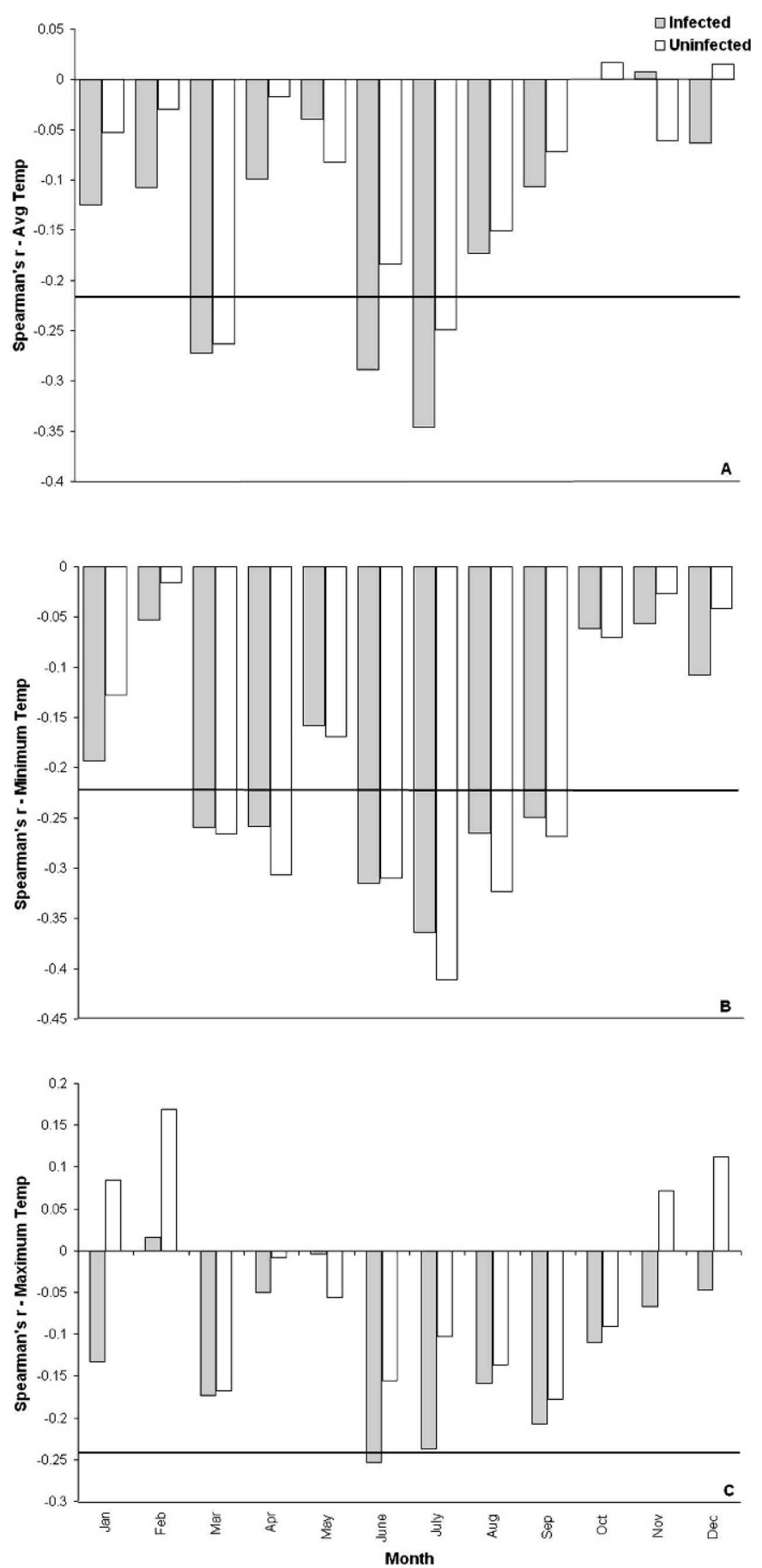

Figure 4. Spearman's correlation coefficients between standardized chronology index value for each year and A: average monthly temperature, B: minimum monthly temperature, C: maximum monthly temperature. The horizontal line indicates the $95 \%$ confidence interval; therefore all correlations below that line are significant $(\mathrm{p}<0.05)$. 


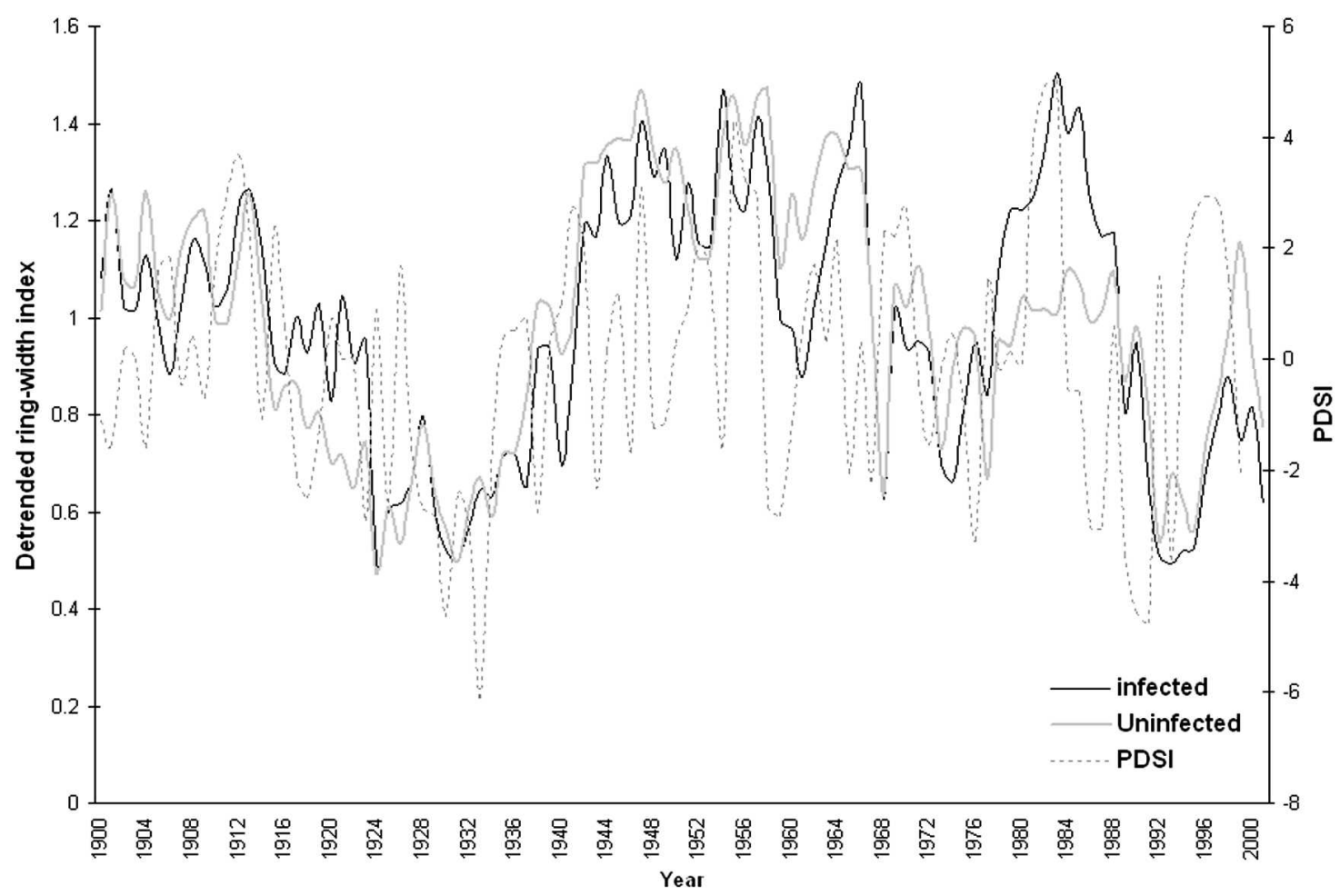

Figure 5. Detrended infected and uninfected chronologies and Palmer Drought Severity Index (PDSI) from 1900-2001. During times of high soil moisture supply (positive PDSI), infected trees grow more rapidly than uninfected trees; conversely, infected trees grow less rapidly than uninfected when moisture supply is low (negative PDSI). Infected trees do not appear to have an advantage over uninfected trees and both grow poorly when the PDSI is very low.

levels to compare with increases in atmospheric carbon dioxide.

High growth rates could also be a function of changes in biomass allocation in infected individuals. Apical growth (height) tends to decrease with mistletoe infection (Knutson 1972; Thomson and Smith 1983), allowing resources to be reallocated to local growth of the main stem and infected branches. Previous studies have demonstrated increased bole taper in infected trees (Tinnin 2001), but I do not have measurements to verify a difference in height between the infected and uninfected samples.

High growth rates of infected trees could be an artifact of the preference of parasites for more vigorous hosts. Recent evidence indicates that the success of dwarf mistletoe depends largely upon the physiological condition of the host trees (Bickford et al. 2005), suggesting that the faster growing trees may be more suitable hosts for the mistletoe. Other studies, however, have found a greater abundance of mistletoe on trees growing in stressful conditions (Gehring and Whitham 1995). Cause and effect cannot be determined without experimental manipulation of infection levels and long-term study of host response.

\section{Mean Sensitivity}

My results do not explain the differences in growth rates between infected and uninfected trees, but they do indicate that infected trees are more sensitive to climate variables. Infected trees at NNVM exhibit higher mean sensitivities and stronger correlations with precipitation and temperature since 1900 . This evidence suggests it may be unnecessary to avoid sampling infected trees for dendrochronological studies, and that infected trees may actually provide stronger climate signals than uninfected samples.

Higher mean sensitivity of infected trees may be a function of changes in water relations caused by mistletoe infection. Sala et al. (2001) found that 
foliage in infected Douglas-fir branches have lower water-use efficiency, but infected trees do not have higher water use overall. Their results indicate that infected trees compensate for lower water-use efficiency by increasing sap flow during times of moderate water availability. Increases in sap flux may not be possible during times of high moisture stress. Changes in sap flux in response to water availability may explain the higher sensitivity and lower growth rates of the infected samples. Piirto et al. (1974) found that annual rings of lodgepole pine infected with dwarf mistletoe had a higher ratio of earlywood to latewood when compared to uninfected samples. A higher percentage of earlywood would lead to greater sapwood volume, but more frequent cavitations during periods of moisture stress, increasing the sensitivity of infected trees to changes in aridity.

\section{Correlations with Climate}

If infected trees are more sensitive to shortterm changes in climate, they may respond more dramatically to global climate change. Consequently, models predicting changes in ponderosa pine distribution under different climate change regimes should consider the influence of dwarf mistletoe on potential range expansions or contractions. There is little information concerning the influence of mistletoe on mature trees or how infection may alter the climate response of host trees (Shea 1962; Hawksworth et al. 1992). If host vigor and productivity control mistletoe productivity, we need to improve our understanding of the interaction between host and parasite to accurately model their response to climate change (Dobbertin 2005). Two possible climate change scenarios are that trees in stressed situations will not support mistletoe populations, or moderate increases in precipitation and temperature could increase the number of trees able to support mistletoe infections, resulting in more widespread infestation.

\section{CONCLUSIONS}

These results indicate that infected ponderosa pine trees are more responsive to climate variation, as demonstrated in higher mean sensitivities and stronger correlations with moisture availability. Previous studies investigated the physiological and morphological effects of mistletoe on host trees, but this study is the first, to my knowledge, to identify the climate response of ponderosa pine trees infected with dwarf mistletoe. These results suggest that ponderosa pine trees infected with mistletoe may provide strong climate signals and do not need to be avoided in dendrochronological studies. It is not clear if the climate response of other mistletoe-host combinations follows the same pattern or if younger infected ponderosa pine trees respond to climate in the same way as my old-growth sample. Additional information about the influence of mistletoe infection on host response to moisture and temperature variation would help us generate more accurate models of the effects of climate change on vegetation in western North America.

We need to better understand how mistletoe alters the physiological response of the host tree throughout its development. The increased sensitivity of host tree-ring series may provide a mechanism for reconstructing mistletoe infection histories in old-growth stands. Dendrochronologists would benefit from being able to identify trees that once supported mistletoe but now have no visible signs of infection. Methods for reconstructing mistletoe infections would be useful for identifying historical changes in mistletoe distributions across western North America and correlating those changes with disturbances such as fire and management practices.

\section{ACKNOWLEDGMENTS}

I thank Keith Hadley, Karen Arabas, Robert Tinnin, Craig Ducey, and anonymous reviewers for their editorial assistance and insightful comments. I also thank Ed Arabas for production of Figure 1.

\section{REFERENCES CITED}

Arabas, K. B., K. S. Hadley, and E. R. Larson, 2006. Fire history of a naturally fragmented landscape in central Oregon. Canadian Journal of Forest Research 36:11081120 . 
Bickford, C. P., T. E. Kolb, and B. W. Geils, 2005. Host physiological condition regulates parasitic plant performance: Arceuthobium vaginatum subsp. cryptopodum on Pinus ponderosa. Oecologia 146:179-189.

Childs, T. W., and E. R. Wilcox, 1966. Dwarf mistletoe effects in mature ponderosa pine forests in south-central Oregon. Journal of Forestry 64:246-250.

Cook, E. R., and R. L. Holmes, 1999. ARSTAN version 1.26, Chronology development. In The International TreeRing Data Bank Program Library User's Manual. University of Arizona Laboratory of Tree-Ring Research, Tucson.

Dobbertin, M., 2005. Tree growth as indicator of tree vitality and of tree reaction to environmental stress: A review. European Journal of Forest Research 124:319-333.

Fisher, J. T., 1983. Water relations of mistletoes and their hosts. In The Biology of Mistletoes, edited by M. Calder, and P. Bernhardt, pp. 161-184. Academic Press, Sydney.

Fritts, H. C., 1976. Tree Rings and Climate. Academic Press, New York, New York.

Gehring, C., and T. Whitham, 1995. Environmental stress influences aboveground pest attack and mycorrhizal mutualism in pinyon-juniper woodlands: implications for management in the event of global warming. In Desired Future Conditions for Pinyon-Juniper Ecosystems, edited by D. W. Shaw, E. F. Aldon, and C. LoSapio, pp. 30-37. USDA Forest Service GTR RM-258.

Geils, B. W., and I. V. Collazo, 2002. Loranthaceae and Viscaceae in North America. In Mistletoes of North American Conifers, edited by B. W. Geils, J. C. Tovar, and B. Moody, pp. 1-5. USDA Forest Service General Technical Report RMRS GTR-98.

Geils, B. W., and F. G. Hawksworth, 2002. Damage, effects, and importance of dwarf mistletoes. In Mistletoes of North American Conifers, edited by B. W. Geils, J. C. Tovar, and B. Moody, pp. 57-65. USDA Forest Service General Technical Report RMRS GTR-98.

Hadley, K. S., and K. B. Arabas, in prep. Succession in a naturally fragmented landscape in central Oregon.

Hawksworth, F. G., W. H. Moir, and J. E. Janssen, 1992. Effects of Dwarf Mistletoe in Old-Growth Lodgepole Pine Stands at Fraser Experimental Forest, Colorado. USDA Forest Service General Technical Report RM-213.

Hawksworth, F. G., and C. G. Shaw, 1984. Damage and loss caused by dwarf mistletoes in coniferous forests of Western North America. In Plant Diseases: Infection, Damage, and Loss, edited by R. K. S. Wood, and G. J. Jellis, pp. 285-297. Blackwell Scientific Publications, Oxford.

Hawksworth, F. G., and D. Wiens, 1996. Dwarf mistletoes: biology, pathology and systematics. USDA Forest Service Agricultural Handbook 709.

Holmes, R. L., 1983. Computer-assisted quality control in treering dating and measurement. Tree-Ring Bulletin 43:6978.

Holmes, R. L., 1994. MEDIR Measuring Software. Laboratory of Tree-Ring Research, The University of Arizona, Tucson.

Knapp, P. A., P. T. Soule, and H. D. Grissino-Mayer, 2001. Detecting potential regional effects of increased atmospheric
$\mathrm{CO}_{2}$ on growth rates of western juniper. Global Change Biology 7:903-917.

Knutson, D. M., 1972. Growth response of dwarf mistletoeinfected ponderosa pine seedling. Phytopathology 62:769.

Knutson, D. M., 1983. Physiology of mistletoe parasitism and disease responses in the host. In The Biology of Mistletoes, edited by M. Calder, and P. Bernhardt, pp. 295-316. Academic Press, Sydney.

Lamont, B., 1983. Mineral nutrition of mistletoes. In The Biology of Mistletoes, edited by M. Calder, and P. Bernhardt, pp. 185-204. Academic Press, Sydney.

NCDC, 2005. National Climate Data Center. Available at: www.ncdc.noaa.gov/oa/ncdc.html.

OCS, 2005. Oregon climate zone data (online). Available at: http://ocs.oce.orst.edu.

Peterson, N. V., and E. A. Groh, 1969. The ages of some Holocene volcanic eruptions in the Newberry Volcano area, Oregon. Oregon Geology 31:73-87.

Piirto, D. D., D. L. Crews, and H. E. Troxell, 1974. The effects of dwarf mistletoe on the wood properties of lodgepole pine. Wood Fiber 6:26-35.

Pohl, K. A., K. S. Hadley, and K. B. Arabas, 2002. A 545-year drought reconstruction for central Oregon. Physical Geography 23:302-320.

Sala, A., E. V. Carey, and R. M. Callaway, 2001. Dwarf mistletoe affects whole-tree water relations of Douglas-fir and western larch primarily through changes in leaf to sapwood ratios. Oecologia 126:42-52.

Shea, K. R., 1962. Diameter increment in old-growth Douglasfir infected by Arceuthobium douglasii. Phytopathology 52: 752

Speer, J. H., 1997. A Dendrochronological Record of Pandora Moth (Coloradia pandora, Blake) Outbreaks in Central Oregon. M.S. thesis, University of Arizona, Tucson.

Stanton, S., 2006. The differential effects of dwarf mistletoe infection and broom abundance on the radial growth of managed ponderosa pine. Forest Ecology and Management 223:318-326.

Stokes, M. A., and T. L. Smiley, 1996. An Introduction to TreeRing Dating. University of Arizona Press, Tucson, Arizona.

Thomson, A. J., J. A. Muir, and K. J. Lewis, 1997. Variability in sub-regional impacts of dwarf mistletoe on mature lodgepole pine. Forestry Chronicle 73:371-375.

Thomson, A. J., and R. B. Smith, 1983. Growth patterns in a young western hemlock plantation infested with dwarf mistletoe. Canadian Journal of Forest Research 13:972-978.

Tinnin, R. O., 2001. Effect of dwarf mistletoe on bole taper and volume in young Douglas-fir. Western Journal of Applied Forestry 16:5-8.

Tinnin, R. O., and D. M. Knutson, 1980. Growth characteristics of the brooms on Douglas-fir caused by Arceuthobium douglasii. Forest Science 26:149-158.

Tocher, R. D., S. W. Gustafson, and D. M. Knutson, 1984. Water metabolism and seedling photosynthesis in dwarf mistletoes. In Biology of Dwarf Mistletoes: Proceedings of the Symposium, edited by F. G. Hawksworth, and R. F. Scharpf, pp. 62-69. USDA Forest Service General Technical Report RM-111. 
Wanner, J. L., and R. O. Tinnin, 1986. Respiration in lodgepole pine parasitized by American dwarf mistletoe. Canadian Journal of Forest Research 16:1375-1378.

Wanner, J. L., and R. O. Tinnin, 1989. Some effects of infection by Arceuthobium americanum on the population dynamics of Pinus contorta in Oregon. Canadian Journal of Forest Research 19:736-742.

Wilson, C. A., and C. L. Calvin, 1996. Anatomy of the dwarf mistletoe shoot system. In Dwarf Mistletoes: Biology,
Pathology, and Systematics, edited by F. G. Hawksworth, and D. Wiens, pp. 95-111. USDA Forest Service Agricultural Handbook 709.

Yamaguchi, D. K., 1991. A simple method for cross-dating increment cores from living trees. Canadian Journal of Forest Research 21:414-416.

Received 31 October 2006; Accepted 20 June 2007. 